\title{
A Review of the Recent Findings in Minimally Invasive Treatment Options for the Management of Occipital Neuralgia
}

\author{
Ivan Urits • Ruben H. Schwartz • Parth Patel • \\ Justin Zeien • Denton Connor · Jamal Hasoon • Amnon A. Berger • \\ Hisham Kassem (D) - Laxmaiah Manchikanti - Alan D. Kaye • \\ Omar Viswanath
}

Received: April 17, 2020 / Published online: June 2, 2020

(C) The Author(s) 2020

\section{ABSTRACT}

Occipital neuralgia $(\mathrm{ON})$ is unilateral or bilateral neuralgia in the dermatomal nerve distribution of the greater, lesser or third occipital nerves and is a very common presentation of

Digital Features To view digital features for this article go to https://doi.org/10.6084/m9.figshare.12340553.

I. Urits $(\bowtie) \cdot J$. Hasoon · A. A. Berger

Department of Anesthesiology, Critical Care, and Pain Medicine, Beth Israel Deaconess Medical Center, Harvard Medical School, Boston, MA, USA e-mail: iurits@bidmc.harvard.edu

\section{R. H. Schwartz · H. Kassem}

Department of Anesthesiology, Mount Sinai

Medical Center, Miami, FL, USA

P. Patel · J. Zeien · O. Viswanath

Department of Anesthesiology, University of Arizona College of Medicine-Phoenix, Phoenix, AZ, USA

D. Connor · O. Viswanath

Department of Anesthesiology, Creighton

University School of Medicine, Omaha, NE, USA

L. Manchikanti

Pain Management Centers of America, Paducah, KY, USA

\section{A. D. Kaye · O. Viswanath}

Department of Anesthesiology, Louisiana State

University Health Shreveport, Shreveport, LA, USA

O. Viswanath

Envision Physician Services, Phoenix, AZ, USA neuropathic pain. ON, although common and well defined, is still a poorly understood pain syndrome. It often requires invasive treatment for long term and significant pain alleviation; however, the evidence supporting different options is still limited. Several minimally invasive techniques have proven to be efficacious and safe, and the selection depends mostly on response to nerve blocks, patient choice and provider preference. This is a comprehensive review of the latest and seminal literature available about occipital neuralgia and currently available minimally invasive treatment options. It covers the anatomical and physiologic biology at the base of neuralgia, the presentation and diagnostic process. It then reviews the available literature to provide description and comparison of the available methods for alleviation.

Keywords: GON; LON; Nerve block; Neuropathic pain; Occipital neuralgia 


\section{Key Summary Points}

Occipital neuralgia, the most common neuropathic pain, is a common, well defined and poorly understood pain syndrome.

It often requires invasive treatment for long-term and significant pain alleviation; however, the evidence supporting different options is still limited.

Here we provide a summary of available methods with supporting evidence.

Several minimally invasive techniques have proven to be efficacious and safe, and the selection depends mostly on response to nerve blocks, patient choice and provider preference.

\section{INTRODUCTION}

Neuralgia is a sharp or stabbing pain that travels along the path of a nerve. A subtype of neuralgia is occipital neuralgia, which is neuralgic pain within the dermatomal region of the occipital nerves [1]. Neuralgia is the most common type of neuropathic pain and was described in 1821 by Beruto and Lentijo and Ramos [2]. According to the newest classification based on the International Headache Society Volume 3 , this pain can be unilateral or bilateral involving the distribution of either the greater, lesser and/or third occipital nerves. There is a broad list of potential causes for occipital neuralgia that includes neurologic, vascular and musculoskeletal sources. As a result, occipital neuralgia must be differentiated from other headache-related disorders to be diagnosed.

The diagnostic criteria include the previously described pain and distribution with the pain having two of the following characteristics: paroxysmal, severe and/or described as sharp, stabbing or shooting. Additionally, the pain must be associated with dysesthesia or allodynia and either tenderness over the nerve distribution or trigger points at the level of the C2 dermatome or along the origin of the greater occipital. Finally, the pain must be temporarily relieved by an anesthetic block to the relevant nerve to diagnose occipital neuralgia $[3,4]$. One study found that all 12 patients with occipital neuralgia had at least $80 \%$ relief of pain with local anesthetic injection [5]. This was one of the first studies that determined that relief from local anesthetic was useful for diagnosis. There are other things that can cause an occipital pattern of pain that mimics occipital neuralgia. These causes must also be ruled out for proper diagnosis. Two such causes are referred pain from skeletal pathology in the atlantoaxial or upper zygapophyseal joints or from pain in neck muscle bodies or their insertions [6].

The relevant anatomy involved in occipital neuralgia is important for both diagnosis and therapeutic intervention. As described previously, the occipital nerves consist of three nerve pairs, the greater occipital nerve $(\mathrm{GON})$, lesser occipital nerve (LON) and third occipital nerve $(\mathrm{TON})$. The origin of the GON is the medial branch of the $\mathrm{C} 2$ dorsal ramus, and it is the largest sensory nerve in the human body $[1,7]$. The GON then bends around and transverses the inferior oblique muscle and usually pierces through the semispinalis capitis muscle and may pierce through the trapezius aponeurosis [7]. The GON pierces the semispinalis capitis in $90 \%$ of cases and pierces the trapezius aponeurosis in $45 \%$ of cases; one of its major functions is to provide cutaneous innervation to the posterior scalp [8]. There are anatomical variants to the GON that need to be considered for diagnosis and treatment [9]. The origin of the LON is the ventral ramus of $\mathrm{C} 2$ and C3 [7]. It moves parallel to the posterior side of the sternocleidomastoid muscle and pierces the deep fascia at the occiput [8]. The origin of the TON is the medial branch of the C3 dorsal ramus [8]. The role of the TON is to provide innervation to the lower occipital scalp and upper neck $[4,7]$.

This is a comprehensive review of the latest and seminal literature available about occipital neuralgia and currently available minimally invasive treatment options. It covers the anatomical and physiologic biology at the base of neuralgia, the presentation and diagnostic process. It then reviews the available literature to 
provide description and comparison of the available methods for alleviation. This article is based on previously conducted studies and does not contain any studies with human participants or animals performed by any of the authors.

\section{EPIDEMIOLOGY}

One 2009 paper studying the incidence of facial pain in the general population cited occipital neuralgia as having a disease-specific incidence rate of 3.2 per 100,000 person years (PY) [95\% CI 2.2-4.5] [10]. They further expanded the data to note that men had an incidence rate of 2.8 [95\% CI 1.6-4.7] and women had an incidence rate of 3.6 [95\% CI 2.2-5.6] [10]. There are no other studies that document incidence or prevalence of occipital neuralgia [4].

There are many different causes of headache, and the constellation of symptoms between these disorders often overlaps. Therefore, it is important to differentiate occipital neuralgia from other conditions in the differential diagnosis such as tension headaches, migraines, cluster headaches and other forms of neuralgia [4]. Once the diagnosis of occipital neuralgia is established using the criteria mentioned above, the etiology must be elucidated. This can also be difficult as the origin of occipital neuralgia is complicated, potentially due to several factors. The exact mechanism and pathophysiology is a debated topic. Potential etiologies include but are not limited to: trauma such as fractures, anatomical issues such as nerve compression or pinching, tumors such as neuromas or osteochondromas, infections such as neurosyphilis, vascular causes such as giant cell arteritis or cervical AV fistulas, and musculoskeletal issues such as C1 or C2 arthrosis $[2,11]$.

To further determine the etiology, imaging is often warranted. Ultrasound is commonly used to evaluate the course of the GON and can be helpful in determining if any part of the occipital nerve appears enlarged or swollen or if an area of entrapment is present [7]. X-ray and computed tomography (CT) can be used to evaluate for potential bony sources. Magnetic resonance imaging (MRI) is usually the imaging of choice as it best visualizes the soft tissues of the occipital and cervical regions [7].

\section{PATHOPHYSIOLOGY}

Occipital headaches, not limited to neuralgia, do not currently have a clear pathophysiology. Many of the suggested mechanisms involve the occipital nerves or their origins at the C2-C3 dorsal root ganglion [12]. Multiple studies have implicated the C2-C3 nerves in occipital neuralgia. In one such paper, C2 and C3 stimulation in ten patients with chronic head pain resulted in occipital pain for $10 / 10$ patients [13]. One potential mechanism of how the $\mathrm{C} 2-\mathrm{C} 3$ nerves are involved was described in a study using an animal model. This study found that axons of neurons in the $\mathrm{C} 2-\mathrm{C} 3$ dorsal root ganglions innervated the dura of the posterior fossa and that around $50 \%$ of them were nociceptive in nature, based on immunoreactivity to calcitonin gene-related peptide; furthermore, when inflammatory mediators such as bradykinin and histamine were administered to the receptive fields of these nerves, there was hypersensitivity to stimulation of the occipital skin [12].

Most cases of occipital neuralgia are spontaneous. There are many theorized mechanisms of how the occipital nerves are affected to cause pain. Most of them involve some irritation or compression to the nerves in some fashion. One study looked at intractable occipital headache after whiplash injury and how surgical release of the GON from where it pierces through the trapezius muscle affected their pain levels. They found that of 18 GON release surgeries, 13 resulted in good or excellent pain relief; however, the relief was not sustained in any of the cases [14]. This indicates that compression and/ or irritation caused by compression of the nerve at the trapezius may be one of the factors involved in occipital neuralgia given that decompressive surgery temporarily relieved pain in most patients.

\section{TREATMENT AND MANAGEMENT}

\section{Conservative Approach}

The initial conservative treatment option for patients with $\mathrm{ON}$ focuses on alleviating muscle tension and postural improvement. Rest, warm 
or cold compresses, massage and physical therapy are recommended treatments for relieving muscle tension [11]. In a retrospective observational study of 34 patients, the use of personalized insoles to improve postural alignment resulted in significantly decreased pain and other symptoms associated with ON [15]. When these approaches fail to resolve the symptoms, medical management is employed next. Nonsteroidal anti-inflammatory drugs (NSAIDs), paracetamol, opioids and muscle relaxants can be used for acute pain; however, these medications only provide transient relief $[1,4]$. Other options for long-term management include selective serotonin reuptake inhibitors (SSRIs) but their efficacy has not been established $[1,16]$. Tricyclic antidepressants (TCAs) and anticonvulsants, such as pregabalin, baclofen, gabapentin, carbamazepine and oxycarbamazepine, were reported to reduce the severity and frequency of $\mathrm{ON}$ episodes [4, 17, 18]. Specifically, gabapentin 300-600 mg at bedtime and nortriptyline $30-50 \mathrm{mg}$ at bedtime are suggested to be effective. Triptans are also recommended because of their efficacy in treating migraines and other types of cervicogenic headache, but there is little evidence supporting this recommendation [19]. Although ergotamine is widely used for migraine, little evidence exists supporting the use of ergot derivatives for ON [1]. Previous research showed that ergotamine treatment provides minimal benefit in alleviating the symptoms of ON [20]. A promising but minimally researched treatment option is infliximab. Similar to rheumatoid arthritis and other inflammatory autoimmune conditions, occipital neuralgia and other types of cervicogenic headache result in increased serum concentrations of tumor necrosis factor (TNF- $\alpha$ ) [21]. Infliximab acts as a monoclonal antibody against TNF- $\alpha$ and has proven successful in treating patients with refractory rheumatoid arthritis [22]. A small study treated patients with severe cervicogenic headache with infliximab and found reduced pain scores [23]. No longer term studies with larger sample sizes have been conducted to further support the use of infliximab for the treatment of $\mathrm{ON}$. There have been studies examining the best target for therapeutic management, and a multidisciplinary approach, including psychosocial support, medical and non-medical interventions, is likely needed to achieve success in this difficult to treat syndrome [24].

\section{Nerve Blocks}

Nerve blocks are an effective tool in the treatment of ON. A prospective study of 44 patients found that occipital nerve blocks significantly reduced pain scores and decreased analgesic medication necessity for at least 6 months postinjection. Patients received either a unilateral or bilateral injection of either both the lesser occipital nerve (LON) and greater occipital nerve (GON) or the GON alone. Analgesic medication requirements in patients who received occipital nerve blocks decreased from $100 \%$ to $16.67 \%$. There was no statistically significant difference in pain scores with lidocaine vs. bupivacaine, demonstrating that the local anesthetic does not affect the efficacy of occipital nerve blocks. All of the nerve blocks were well tolerated except for one patient who experienced transient dizziness and nausea [25]. A case series consisting of three patients with occipital neuralgia secondary to sports-related concussion yielded similar results. Three patients (two teenagers and one adult) were treated using unilateral blocks of the GON, resulting in $100 \%$ relief of all symptoms. The relief varied from $8 \mathrm{~h}$ to 2 months [26]. Another case series consisting of 14 teenage patients with post-concussion syndrome and subsequent ON substantiated the efficacy of occipital nerve blocks. Patients received greater occipital nerve blocks with a lidocaine and triamcinolone solution (most often bilaterally). There was a reduction in headache frequency of $\geq 50 \%$ in $64 \%$ of patients, and mean headache frequency decreased from 26 to 17 days per month. Improvements were also noted in concussion symptomatology and quality of life. The procedure was well tolerated with only one patient experiencing temporary alopecia [27]. A recent review of seven pediatric studies found that GON blocks have excellent efficacy in alleviating the symptoms of primary chronic 
headaches, including ON. Lidocaine was the preferred anesthetic and the value of concurrent steroids was indeterminate [28]. A review of 21 studies came to a similar conclusion that occipital nerve blocks are an effective treatment for ON [29]. The use of the GON block has been proposed as a transitional treatment bridge for patients who would benefit from invasive neurostimualtion implants in the future [30].

The incorporation of advanced imaging techniques, such as ultrasound guided, CT guided and MR guided, has improved the effectiveness of occipital nerve blocks. Traditionally, palpation of anatomic landmarks was used to find the GON or LON and avoid the occipital artery. There is evidence to suggest that ultrasound-guided GON blocks yield greater shortterm efficacy than the traditional landmark palpation technique [31]. Two case reports of patients with chronic ON demonstrated the benefit of using ultrasound to guide diagnostic GON blocks and pulsed radiofrequency ablation (PRFA) treatment. Both patients had no complications during the procedure and experienced immediate long-term relief from $\mathrm{ON}$ symptoms [32]. A prospective open-label study involving 14 patients with either cervicogenic headache or ON showed successful blockade of the GON at the level of $\mathrm{C} 2$ using ultrasound guidance with no complications. Mean pain scores decreased from 4.71 at baseline to 0.93 immediately post-procedure to 2.50 at the 4-week follow-up [33].

CT-guided nerve blocks are another promising treatment for ON. A retrospective study of 17 patients with refractory ON showed immediate pain relief after undergoing CT fluoroscopy-guided unilateral or bilateral $\mathrm{C} 2$ or $\mathrm{C} 2$ and $\mathrm{C} 3$ nerve root blocks. All patients had relief from $\mathrm{ON}$ pain for $1-4 \mathrm{~h}$ post-nerve block, and there were no complications other than one patient who had vasovagal syncope [34]. Another retrospective study of 33 patients with refractory $\mathrm{ON}$ found $\geq 50 \%$ pain relief lasting for at least 3 months in $86 \%$ of patients. Patients received left GON, right GON, or bilateral GON blocks depending on their symptoms. In the $86 \%$ of patients who achieved $\geq 50 \%$ pain relief, the mean duration of pain relief was 9.15 months. No major complications were encountered; however, minor complications, such as transient cervicalgia, vasovagal syncope, temporary blurred vision and transient neck torticollis, occurred in $21 \%$ of patients [35].

The evolution of occipital nerve blocks has continued through the emergence of MR guidance. In a prospective study of 11 patients with chronic refractory cranio-facial pain syndromes, such as ON, who received GON blocks using MR guidance, $63 \%$ achieved $\geq 50 \%$ pain reduction at 1 month. The mean self-rated improvement in pain was $78 \%$, and no complications were reported other than one patient experiencing transient vasovagal syncope. The study showed that MR-guided GON blocks are feasible and may serve as a useful complement to current techniques, particularly in young patients and patients who receive multiple GON blocks [36].

\section{Botox Injections}

Botox injections have historically been used to treat migraines, spasticity and focal dystonia, with a growing interest in its utilization as therapy for neuropathic pain conditions, such as ON [37]. The injections are typically done subcutaneously at multiple sites over the area of associated pain. A case report of a patient with chronic migraine and associated refractory $\mathrm{ON}$ in the GON distribution found complete pain relief after injection of botulinum toxin type-A (BTX-A). The BTX-A injection was revealed to be more effective than blocks with corticosteroids and other analgesic formulations [38]. A retrospective case series of six patients with refractory $\mathrm{ON}$ also demonstrated the efficacy and superiority of BTX-A injections. There was a significant improvement in pain scores and functional capacity after injection of BTX-A, with a mean duration of pain relief at $>$ 4 months. Comparatively, diagnostic bupivacaine occipital nerve blocks resulted in only short-term pain relief with an average of about 2 weeks [39].

A prospective case series of six patients with chronic ON further demonstrated the effectiveness of BTX-A injections in pain relief. Patients received BTX-A injections in the GON 
and LON distributions with subsequent assessment of types of pain, quality of life and pain medication usage for 12 weeks post-injection. Patients reported significant improvements in sharp/shooting pain, which is characteristic of ON, during weeks 2-3 and weeks 7-12, and pins/needles pain during weeks 3-6. Quality of life measures, including headache-specific quality of life, significantly improved as well. However, none of the patients reported immediate cessation of ON symptoms after injection, and there was no significant improvement in dull/achy pain. Patients also reported no significant reduction in analgesia usage post-injection [40]. A recent review concluded that there is insufficient evidence to prove BTX-A injections are an effective therapy for ON [37].

However, new research has emerged supporting the utilization of BTX-A injections as therapy for ON. A retrospective review of 33 patients with severe ON demonstrated significant pain relief after BTX-A injection. After a follow-up period of 6 months, $80 \%$ of patients described the final result as excellent (i.e., total pain relief) or very positive (i.e., nearly complete pain relief), with all patients reporting significant improvement in quality of life [41]. In addition, a recently published retrospective study was completed involving 30 post-9/11 combat veterans with deployment-related traumatic brain injury or neck trauma, chronic migraine and $\mathrm{ON}$. All veterans received occipital nerve blocks in the GON and LON and BTX-A injections within 6 months of their diagnosis. Prior to treatment, the mean number of headache days was 24.1. Post-treatment, the mean number of headache days decreased to 12.9 with a mean difference of headache days pre- to post-treatment of 11.2. This study concluded that dual therapy with occipital nerve blocks and BTX-A injections is an effective therapy for veterans with chronic migraine and $\mathrm{ON}$ [42].

\section{RADIOFREQUENCY ABLATION/ CRYOABLATION}

Several modalities of radiofrequency ablation (RFA) are used to treat chronic pain conditions $[43,44]$. These include thermal radiofrequency ablation (TRF), pulsed radiofrequency (PRF), cryoablation and cryoneurolysis. By targeting the nociceptive nerve conduction pathways, a lesion is introduced that prevents nociceptive output from $A-\delta$ and $C$ fibers while preserving motor and sensory signaling. However, adverse events can occur in 12-13\% of cases; therefore, RFA is typically reserved for patients who fail conservative treatment [7].

\section{Thermal Radiofrequency Ablation}

TRF involves 20 gauge $50-\mathrm{mm}$ insulated needles placed in proximity to the greater and lesser occipital nerves. Once placed, a $50-\mathrm{Hz}$ sensory stimulus is used to confirm correct location. TRF is then carried out at $80^{\circ} \mathrm{C}$ for $180 \mathrm{~s}$ in lesion mode. In a retrospective study, Hoffman et al. analyzed pain reduction in 39 patients treated for occipital neuralgia with TRF using the visual analog scale (VAS) [45]. There was a significant difference in preprocedure pain score (6.7) and 1 -month post procedure (2.7) with a mean pain reduction of $4.0 \pm 3.3$. The mean patient reported pain relief was $76.3 \%$ and the mean length of relief was 6.5 months. These findings suggest that TRF may reduce pain scores in patients with occipital neuralgia for 6 months.

\section{Greater Occipital Nerve Cryoneurolysis in the Management of Intractable Occipital Neuralgia}

Kastler et al. conducted an observational study in which seven patients were subjected to CTguided cryoneurolysis for ON after failing conservative treatments [46]. At 1 week all patients had significant pain alleviation of $>50 \%$ on the VAS scale. At 3 months post procedure, five of seven had continued pain benefit. In six of the patients, their ON returned to baseline suggesting more invasive management may be necessary.

\section{Pulsed Radiofrequency in Chronic Pain}

PRF of the greater and lesser occipital nerve has been shown to improve $\mathrm{ON}$ pain. In a case report, PRF was shown to decrease pain by $70 \%$ 
at 4 months and after retreatment there was $70 \%$ pain reduction at 5 months [47]. Choi et al. demonstrated the long-term efficacy of PRF, which caused a 6-month reduction in mean VAS from 6.9 to 0.8 and Total Pain Index score from 232.7 to 40.6 [48]. Additionally, a prospective trial demonstrated a $50 \%$ reduction of pain at 6 months in $52.6 \%$ of patients. Compared with steroid injections of the occipital nerves in a randomized, double-blind study, pain reduction in the PRF group was significantly greater than that of the steroid injection group and remained superior through 6-month follow-up [49]. PRF has also shown improvement in quality of life by improving sleep and mood disturbance and disturbance of daily living [50]. Treatment of ON with PRF demonstrates significant pain reduction without serious adverse events.

\section{Radiofrequency Denaturation}

Radiofrequency denaturation of the greater occipital nerve was performed on 78 patients with $\mathrm{ON}$ [41]. Half of these patients reported complete disappearance of symptoms, and $85.4 \%$ reported excellent or good results over the long term, with an average follow-up of 22 months. However, the remaining 14.6\% reported average or poor results and required further treatment. There were two serious complications observed during this trial. One involved a tetra-ventricular hemorrhage leading to death, and the other involved the appearance of Brown-Sequard syndrome leading to hemiparalysis. While radiofrequency denaturation does yield reduced pain, the risk of complications warrants investigation of other treatment modalities.

\section{Cooled Radiofrequency Ablation for Bilateral Greater Occipital Neuralgia}

Cooled radiofrequency ablation is a new alternative to TRF and PRF and may be considered because of its long-term pain alleviation and reduced side effect profile. In a case of a 35-yearold woman with 2.5 year bilateral $\mathrm{ON}$ who failed multiple other treatment options, cooled
RFA was performed causing $100 \%$ pain reduction immediately and $75 \%$ reduction in $24 \mathrm{~h}$ [51]. Further follow-up is required to understand the full effect.

\section{PERIPHERAL NERVE STIMULATION}

Peripheral nerve stimulation (PNS) is used in a variety of chronic pain conditions that are not resolved by conservative therapies. It is widely believed that PNS works by stimulation of the A- $\delta$ fibers, which inhibit the nociceptive input and transmission of the $\mathrm{C}$ fibers to the cortex [52]. Constant stimulation of the A- $\delta$ fibers blocks the transmission of pain at the level of the spinal cord and the medulla. In addition to the typical complications associated with surgery, common complications include placement of the implantable pulse generator in the wrong compartment, injury to the nerve during electrode placement and electrode migration. PNS has primarily been used for spinal cord stimulation alone; however, the potential for its translation into $\mathrm{ON}$ and other chronic pain conditions is promising.

The use of PNS in treatment of ON is highly favorable because of its low invasiveness, adjustable settings and ease of removal. There is limited research on its use in the treatment of $\mathrm{ON}$, but it has proven efficacious in treatment of other conditions. In a recent analysis of its use in $\mathrm{ON}$, there was a Level III recommendation that in 76 patients the majority had a favorable long-term outcome [53].

In a retrospective review of 29 patients with refractory ON treated with a trial of PNS, 20 patients had beneficial results and proceeded to full implantation [54]. Of these patients, there was an overall success rate of $85 \%$, and the mean VAS score dropped from 7.4 to 2.9. The remaining nine patients required repair or replacement of pervious systems or did not have a benefit from the trial. Complications arose in 4 of the 29 patients, which included infection, hardware erosion, loss of effect and lead migration leading to repair or removal of the device.

This treatment has also been studied in prevention of cluster headaches and migraines. To 
date, there have not been any randomized control trials testing the efficacy of occipital nerve PNS in cluster headaches. However, there are studies suggesting that up to $90 \%$ of patients had a reduction in attack frequency allowing less use of preventive medications with observed effects up to 9 years [55]. Nevertheless, there is no control group to compare the results against. In a randomized controlled trial for chronic migraines treated with occipital nerve PNS, $17.1 \%$ of patients reported a $50 \%$ reduction in migraine intensity compared with $13.5 \%$ of the control group. Additionally, there was a significant reduction in the number of migraine days and disability. In an extension of this trial, $47.8 \%$ of patients reported a 50\% reduction in migraine intensity, and there was a significant reduction in frequency of migraines [56-58]. Moreover, a retrospective review of occipital nerve stimulation in refractory headache syndromes reported $>50 \%$ reduction in pain intensity and/or frequency at 28-31 months [59].

Another study analyzed the use of supraorbital occipital nerve stimulation in patients with chronic headache disorders. Over the course of 7 years, 25 patients were retrospectively followed after PNS, 11 patients were followed long term, and $82 \%$ of patients had a $>50 \%$ pain reduction [60]. There was an average VAS pain reduction from 7.1 to 3.3 . Although there were positive results, like the aforementioned studies there was a high rate of complications including infection, erosion and loss of effect. Guzzi et al. further described the use of PNS in the setting of refractory pain following occiptocervical fusion surgery. The study found that there was a high rate of $>50 \%$ pain reduction in this patient group but there were also a high rate of complications [61]. Overall, PNS is an effective treatment for refractory occipital pain yielding improved quality of life and reduced need for pharmaceuticals. However, due to the high rate of complications, further studies into implantation techniques and stimulation technology would benefit practical use of this modality.

\section{Surgical Management}

Surgical treatment for $\mathrm{ON}$ is generally reserved as a last resort after medical management and other minimally invasive interventions have failed, such as injections and pulsed radiofrequency ablation [1]. One surgical option is GON decompression. In a prospective study of 11 patients with refractory ON, GON decompression was done with pre- and post-assessment of pain. Before surgery, patients reported 17.1 mean pain episodes per month with a mean pain intensity of $7.18 / 10$. Post-surgery, there were 4.1 mean pain episodes per month with a mean pain intensity of $1.73 / 10$. After a mean follow-up period of 12.45 months, three patients reported complete relief of symptoms, six reported significant improvement in symptoms, and two reported lack of any significant improvement. Six patients experienced transient surgical site paresthesias but no other complications were noted [62]. A case report of a patient with refractory $\mathrm{ON}$ who underwent right GON decompression demonstrated similar results. The patient reported complete pain relief after a follow-up period of $>1$ year, and the only post-procedure complication was mild wound site pain [63].

For patients with ON refractory to GON decompression, GON excision is a viable surgical option. A retrospective review of 71 patients with ON refractory to GON decompression demonstrated a $70.4 \%$ success rate of GON excision. A follow-up survey (mean follow-up of 33 months) showed $41 \%$ of patients achieved $\geq$ $90 \%$ reduction in headache severity as measured by the migraine headache index (MHI). The MHI changed, on average, from 146 to 49, translating to an average reduction of $63 \%$. Additionally, migraine disability scores reduced by an average of $49 \%$ with $31 \%$ of patients reporting numbness or hypersensitivity in the treated area [64].

A variant of the GON excision procedure exists in which the GON is excised and the inferior oblique muscle of the neck is sectioned. A retrospective study of ten patients with refractory $\mathrm{ON}$ who underwent this procedure was conducted. Preoperatively, the mean pain score was $70 \%$. At 3-month follow-up, mean 
pain score dropped to $30 \%$. At the final mean follow-up of 37 months, mean pain score reduced to $20 \%$. There were no complications other than one patient who developed residual facet joint syndrome. Analgesic use decreased in all patients, and $70 \%$ of patients were very satisfied or satisfied with the results of the procedure [65].

Researchers have also found positive results from excising both the GON and LON or the GON, LON and great auricular nerve. A retrospective review of 206 patients with chronic ON who underwent either GON, LON, or GON and LON excision showed that $80.5 \%$ of patients experienced at least $50 \%$ pain relief at a followup minimum of 12 months. In $43.4 \%$ of patients, complete pain relief was reported. Two patients had complications, both being incisional cellulitis [64]. Another retrospective review of 22 patients with intractable $\mathrm{ON}$ who underwent GON, LON and great auricular nerve excision revealed that $91 \%$ of patients experienced complete relief of pain post-surgery and $9 \%$ reported a significant reduction in pain. Two patients had recurrence of pain at 6-8 weeks post-surgery, necessitating a second operation. At 18 months post-surgery, $68 \%$ of patients still had total pain relief, $18 \%$ had occasional episodes of mild pain, and $14 \%$ had frequent episodes of pain requiring regular analgesics, one of whom experienced scalp hypersensitivity and dysesthesia secondary to surgery complications [66].

Intradural cervical dorsal rhizotomy is another feasible option as evidenced by a retrospective study of 17 patients with refractory ON who underwent unilateral or bilateral intradural C1, C2, C3 or C4 dorsal rhizotomies. Immediately after surgery, all patients had complete pain relief. After a mean follow-up period of 20 months, $64.7 \%$ still had total pain relief, $11.8 \%$ had partial relief, and $23.5 \%$ had no relief [34].

The final surgical option for refractory $\mathrm{ON}$ is cervical ganglionectomy. A retrospective review of 29 patients who underwent either C2 nerve root decompression, C2 dorsal root ganglionectomy or decompression followed by ganglionectomy showed similar decreases in mean pain ratings post-surgery. At almost
2 months follow-up, $66 \%$ of patients reported improved or total pain relief. Among the 19 patients who participated in the longer followup assessment (mean follow-up of 5.6 years), $68 \%$ rated the operative outcomes as very good or satisfactory. The study shows that $\mathrm{C} 2$ nerve root decompression, C2 dorsal root ganglionectomy and C2 nerve root decompression followed by salvage $\mathrm{C} 2$ ganglionectomy yield similarly favorable postoperative pain relief and are viable surgical options for refractory $\mathrm{ON}$ [67]. Another retrospective review of 20 patients with intractable ON who underwent $\mathrm{C} 2$ and/or C3 ganglionectomies demonstrated excellent short-term pain relief in $95 \%$ of patients postsurgery. At long-term follow-up (mean 42.5 months), four reported complete pain relief, eight reported 50-90\% improvement in pain, and eight reported $<50 \%$ improvement in pain [68].

\section{CONCLUSION}

$\mathrm{ON}$ is a condition that may have a low incidence but can be greatly disabling and affect the quality of life of those ailing from this condition. Many of the current treatments have proven ineffective or provide temporary relief leading to recurring pain and increased morbidity. Historically, conservative treatments such as medications and alternative therapies are first line; however, many patients fail conservative management and experience refractory symptoms. Local injections with corticosteroids provide pain relief but are only temporarily effective leading to frequent injections. As a result, treatment of $\mathrm{ON}$ is a challenging matter, and novel therapies are necessary to improve outcomes. Nerve blocks, Botox injection, radiofrequency ablation, peripheral nerve stimulation and surgical management have proven to have varying degrees of efficacy; however, they do demonstrate the potential benefits of decreased recurrence, increased functionality and overall improvement compared with conservative treatments. At this early stage of study, further investigation is required to elucidate a complete understanding of the true efficacy of these therapy options. 
As of now, the risk of complications is relatively high, but improved technology and technique may provide a novel cure to this disabling condition.

\section{ACKNOWLEDGEMENTS}

Funding. No funding or sponsorship was received for this study or publication of this article.

Authorship. All named authors meet the International Committee of Medical Journal Editors (ICMJE) criteria for authorship for this article, take responsibility for the integrity of the work as a whole, and have given their approval for this version to be published.

Disclosures. Ivan Urits, Ruben H. Schwartz, Parth Patel, Justin Zeien, Denton Connor, Jamal Hasoon, Amnon A. Berger, Hisham Kassem, Laxmaiah Manchikanti, Alan D. Kaye and Omar Viswanath have nothing to disclose.

Compliance with Ethics Guidelines. This article is based on previously conducted studies and does not contain any studies with human participants or animals performed by any of the authors

Data Availability. Data sharing is not applicable to this article as no datasets were generated or analyzed during the current study.

Open Access. This article is licensed under a Creative Commons Attribution-NonCommercial 4.0 International License, which permits any non-commercial use, sharing, adaptation, distribution and reproduction in any medium or format, as long as you give appropriate credit to the original author(s) and the source, provide a link to the Creative Commons licence, and indicate if changes were made. The images or other third party material in this article are included in the article's Creative Commons licence, unless indicated otherwise in a credit line to the material. If material is not included in the article's Creative Commons licence and your intended use is not permitted by statutory regulation or exceeds the permitted use, you will need to obtain permission directly from the copyright holder. To view a copy of this licence, visit http://creativecommons.org/licenses/by$\mathrm{nc} / 4.0 /$.

\section{REFERENCES}

1. Choi I, Jeon SR. Neuralgias of the head: occipital neuralgia. J Korean Med Sci. 2016;31:479-88.

2. López-Soto PJ, Bretones-García JM, Arroyo-García V, García-Ruiz M, Sánchez-Ossorio E, RodríguezBorrego MA. Occipital neuralgia: a noninvasive therapeutic approach. Rev Lat Am Enfermagem. 2018;26:e3067.

3. Narouze S. Occipital neuralgia diagnosis and treatment: the role of ultrasound. Headache. 2016;56: 801-7.

4. Dougherty C. Occipital neuralgia. Curr Pain Headache Rep. 2014;18(5):411.

5. Kuhn WF, Kuhn SC, Gilberstadt H. Occipital neuralgias: clinical recognition of a complicated headache. A case series and literature review. J Orofac Pain. 1997;11:158-65.

6. Headache Classification Committee of the International Headache Society (IHS). The International classification of headache disorders, 3rd edition. Cephalalgia. 2018;38(1):1-211.

7. Barmherzig R, Kingston W. Occipital neuralgia and cervicogenic headache: diagnosis and management. Curr Neurol Neurosci Rep. 2019;19:20.

8. Cohen-Gadol A, Kemp III W, Tubbs RS. The innervation of the scalp: a comprehensive review including anatomy, pathology, and neurosurgical correlates. Surg Neurol Int. 2011.

9. Won HJ, Ji HJ, Song JK, Kim YD, Won HS. Topographical study of the trapezius muscle, greater occipital nerve, and occipital artery for facilitating blockade of the greater occipital nerve. PLoS One. 2018.

10. Koopman JSHA, Dieleman JP, Huygen FJ, de Mos M, Martin CGM, Sturkenboom MCJM. Incidence of facial pain in the general population. Pain. 2009; 147:122-7. 
11. Vanelderen P, Lataster A, Levy R, Mekhail N, Van Kleef M, Van Zundert J. 8. Occipital neuralgia. Pain Pract. 2010;10(2):137-44.

12. Noseda R, Melo-Carrillo A, Nir RR, Strassman AM, Burstein R. Non-trigeminal nociceptive innervation of the posterior dura: implications to occipital headache. J Neurosci. 2019;39:1867-80.

13. Johnston MM, Jordan SE, Charles AC. Pain referral patterns of the $\mathrm{C} 1$ to $\mathrm{C} 3$ nerves: implications for headache disorders. Ann Neurol. 2013;74:145-8.

14. Magńsson T, Ragnarsson T, Björnsson A. Occipital nerve release in patients with whiplash trauma and occipital neuralgia. Headache. 1996;36:32-6.

15. López-Soto PJ, Bretones-García JM, Arroyo-García V, García-Ruiz M, Sánchez-Ossorio E, RodríguezBorrego MA, López-Soto PJ, Bretones-García JM, Arroyo-García V, García-Ruiz M, Sánchez-Ossorio E, Rodríguez-Borrego MA. Occipital neuralgia: a noninvasive therapeutic approach. Rev Lat Am Enfermagem. 2018;26.

16. Martelletti P, van Suijlekom H. Cervicogenic headache. CNS Drugs. 2004;18(12):793-805.

17. Viswanath O, Urits I, Jones MR, Peck JM, Kochanski J, Hasegawa M, Anyama B, Kaye AD. Membrane stabilizer medications in the treatment of chronic neuropathic pain: a comprehensive review. Curr Pain Headache Rep. 2019;23:37.

18. Urits I, Peck J, Orhurhu MS, Wolf J, Patel R, Orhurhu V, Kaye AD, Viswanath O. Off-label antidepressant use for treatment and management of chronic pain: evolving understanding and comprehensive review. Curr Pain Headache Rep. 2019;23:66.

19. Trescot AM. Headache management in an interventional pain practice. Association of Pain Management Anesthesiologists. Pain Phys. 2000;3:127.

20. Bovim G, Sjaastad O. Cervicogenic headache: responses to nitroglycerin, oxygen, ergotamine and morphine. Headache J Head Face Pain. 1993;33(5): 249-52.

21. Martelletti P. Proinflammatory pathways in cervicogenic headache. Clin Exp Rheumatol. 2000;18(2 Suppl 19):S33-8.

22. Russell A, Haraoui B, Keystone E, Klinkhoff A. Current and emerging therapies for rheumatoid arthritis, with a focus on infliximab: clinical impact on joint damage and cost of care in Canada. Clin Ther. 2001;23(11):1824-38 (discussion 1791).
23. Martelletti P. Inflammatory mechanisms in cervicogenic headache: an integrative view. Curr Pain Headache Rep. 2002;6(4):315-9.

24. Viswanath O, Urits I, Burns J, Charipova K, Gress K, McNally A, Urman RD, Welschmeyer A, Berger AA, Kassem H, Sanchez MG, Kaye AD, Eubanks TN, Cornett EM, Ngo AL. Central neuropathic mechanisms in pain signaling pathways: current evidence and recommendations. Adv Ther. 2020.

25. Juškys R, Šustickas G. Effectiveness of treatment of occipital neuralgia using the nerve block technique: a prospective analysis of 44 patients. Acta Med Litu. 2018;25(2):53-60.

26. Zaremski JL, Hurley RW, Herman D, Bauer RM, Ahn $\mathrm{AH}$. Poster 182 occipital neuralgia blockade as a treatment after concussions. A case series. PM\&R. 2014;6(9):S249.

27. Seeger TA, Orr S, Bodell L, Lockyer L, Rajapakse T, Barlow KM. Occipital nerve blocks for pediatric posttraumatic headache. J Child Neurol. 2015;30(9):1142-6.

28. Dubrovsky AS. Nerve blocks in pediatric and adolescent headache disorders. Curr Pain Headache Rep. 2017;21(12):50.

29. Tobin J, Flitman S. Occipital nerve blocks: when and what to inject? Headache J Head Face Pain. 2009;49(10):1521-33.

30. Martelletti P, Giamberardino MA, Mitsikostas DD. Greater occipital nerve as target for refractory chronic headaches: from corticosteroid block to invasive neurostimulation and back. Expert Rev Neurother. 2016;16:865-6.

31. Shim JH, Ko SY, Bang MR, Jeon WJ, Cho SY, Yeom JH, Shin WJ, Kim KH, Shim J-C. Ultrasound-guided greater occipital nerve block for patients with occipital headache and short term follow up. Korean J Anesthesiol. 2011;61(1):50.

32. David Vanderhoek M, Hoang HT, Goff B, Vanderhoek MD. Ultrasound-guided greater occipital nerve blocks and pulsed radiofrequency ablation for diagnosis and treatment of occipital neuralgia. Anesthesiol Pain Med. 2013;3(2):256-65.

33. Pingree MJ, Sole JS, O'Brien TG, Eldrige JS, Moeschler SM. Clinical efficacy of an ultrasoundguided greater occipital nerve block at the level of C2. Reg Anesth Pain Med. 2017;42(1):99-104.

34. Kapoor V, Rothfus WE, Grahovac SZ, Amin Kassam SZ, Horowitz MB. Refractory occipital neuralgia: preoperative assessment with CT-guided nerve block prior to dorsal cervical rhizotomy. AJNR Am J Neuroradiol. 2003;24(10):2105-10. 
35. Kastler A, Onana Y, Comte A, Attyé A, Lajoie J-L, Kastler B. A simplified CT-guided approach for greater occipital nerve infiltration in the management of occipital neuralgia. Eur Radiol. 2015;25(8): 2512-8.

36. Kastler A, Perolat R, Kastler B, Maindet-Dominici C, Fritz J, Benabid AL, Chabardes S, Krainik A. Greater occipital nerve infiltration under MR guidance: feasibility study and preliminary results. Eur Radiol. 2018;28(2):886-93.

37. Oh H-M, Chung M. Botulinum toxin for neuropathic pain: a review of the literature. Toxins (Basel). 2015;7(8):3127-54.

38. Volcy M, Tepper S, Rapoport A, Sheftell F, Bigal M. Botulinum toxin $\mathrm{A}$ for the treatment of greater occipital neuralgia and trigeminal neuralgia. Cephalalgia. 2006;26(3):336-40.

39. Kapural L, Stillman M, Kapural M, McIntyre P, Guirgius M, Mekhail N. Botulinum toxin occipital nerve block for the treatment of severe occipital neuralgia: a case series. Pain Pract. 2007;7(4): 337-40.

40. Taylor M, Silva S, Cottrell C. Botulinum toxin typeA (BOTOX) in the treatment of occipital neuralgia: a pilot study. Headache. 2008;48(10):1476-81.

41. Finiels P-J, Batifol D. The treatment of occipital neuralgia: review of 111 cases. Neurochirurgie. 2016;62:233-40.

42. Williams KA, Lawson RM, Perurena OH, Coppin JD. Management of chronic migraine and occipital neuralgia in post 9/11 combat veterans. Mil Med. 2019;184(7-8):e207-11.

43. Urits I, Jones M, Patel R, Adamian L, Seifert D, Thompson W, Viswanath O. Minimally invasive interventional management of osteoarthritic chronic knee pain. J Knee Surg. 2018;32:72.

44. Orhurhu V, Urits I, Orman S, Viswanath O, AbdElsayed A. A systematic review of radiofrequency treatment of the ankle for the management of chronic foot and ankle pain. Curr Pain Headache Rep. 2019;23(1):4.

45. Hoffman LM, Abd-Elsayed A, Burroughs TJ, Sachdeva $H$. Treatment of occipital neuralgia by thermal radiofrequency ablation. Ochsner J. 2018;18(3): 209-14.

46. Kastler A, Attyé A, Maindet C, Nicot B, Gay E, Kastler B, Krainik A. Greater occipital nerve cryoneurolysis in the management of intractable occipital neuralgia. J Neuroradiol. 2018;45(6):386-90.
47. Vanneste T, Van Lantschoot A, Van Boxem K, Van Zundert J. Pulsed radiofrequency in chronic pain. Curr Opin Anaesthesiol. 2017;30(5):577-82.

48. Choi HJ, Oh IH, Choi SK, Lim YJ. Clinical outcomes of pulsed radiofrequency neuromodulation for the treatment of occipital neuralgia. J Korean Neurosurg Soc. 2012;51(5):281-5.

49. Cohen SP, Lee Peterlin B, Fulton L, Neely ET, Kurihara C, Gupta A, Mali J, Fu DC, Jacobs MB, Plunkett AR, Verdun AJ, Stojanovic MP, Hanling S, Constantinescu O, White RL, McLean BC, Pasquina PF, Zhao Z. Randomized, double-blind, comparativeeffectiveness study comparing pulsed radiofrequency to steroid injections for occipital neuralgia or migraine with occipital nerve tenderness. Pain. 2015;156(12):2585-94.

50. Manolitsis N, Elahi F. Pulsed radiofrequency for occipital neuralgia. Pain Physician. 2014;17(6): E709-17.

51. Vu T, Chhatre A. Cooled radiofrequency ablation for bilateral greater occipital neuralgia. Case Rep Neurol Med. 2014;2014:1-4.

52. Harsh V, Mishra P, Gond PK, Kumar A. Peripheral nerve stimulation: black, white and shades of grey. Br J Neurosurg. 2019;33:332-6.

53. Slavin KV, Isagulyan ED, Gomez C, Yin D. Occipital nerve stimulation. Neurosurg Clin $\mathrm{N}$ Am. 2019;30(2):211-7.

54. Keifer OP, Diaz A, Campbell M, Bezchlibnyk YB, Boulis NM. Occipital nerve stimulation for the treatment of refractory occipital neuralgia: a case series. World Neurosurg. 2017;105:599-604.

55. Hoffmann J, May A. Neuromodulation for the treatment of primary headache syndromes. Expert Rev Neurother. 2019;19(3):261-8.

56. Saper JR, Dodick DW, Silberstein SD, McCarville S, Sun M, Goadsby PJ. Occipital nerve stimulation for the treatment of intractable chronic migraine headache: ONSTIM feasibility study. Cephalalgia. 2011;31(3):271-85.

57. Silberstein SD, Dodick DW, Saper J, Huh B, Slavin KV, Sharan A, Reed K, Narouze S, Mogilner A, Goldstein J, Trentman T, Vaisman J, Ordia J, Weber P, Deer T, Levy R, Diaz RL, Mekhail N. Safety and efficacy of peripheral nerve stimulation of the occipital nerves for the management of chronic migraine: results from a randomized, multicenter, double-blinded, controlled study. Cephalalgia. 2012;32(16):1165-79.

58. Dodick DW, Silberstein SD, Reed KL, Deer TR, Slavin KV, Huh B, Sharan AD, Narouze S, Mogilner AY, 
Trentman TL, Ordia J, Vaisman J, Goldstein J, Mekhail N. Safety and efficacy of peripheral nerve stimulation of the occipital nerves for the management of chronic migraine: long-term results from a randomized, multicenter, double-blinded, controlled study. Cephalalgia. 2015;35(4):344-58.

59. Palmisani S, Al-Kaisy A, Arcioni R, Smith T, Negro A, Lambru G, Bandikatla V, Carson E, Martelletti P. A six year retrospective review of occipital nerve stimulation practice-controversies and challenges of an emerging technique for treating refractory headache syndromes. J Headache Pain. 2013;14:67.

60. Jiang JF, Diaz AN, Campbell M, Boulis NM, Keifer OP. Supraorbital occipital circumferential stimulation for the treatment of refractory chronic primary headache: a case series. World Neurosurg. 2019;124:e417-23.

61. Guzzi G, Della Torre A, Gabriele D, Volpentesta G, Chirchiglia D, Stroscio CA, Lavano A. Occipital nerve stimulation for refractory pain after occipitocervical fusion. Acta neurochirurgica, supplementum. Wien: Springer; 2019. p. 365-7.

62. Jose A, Nagori SA, Chattopadhyay PK, Roychoudhury A. Greater occipital nerve decompression for occipital neuralgia. J Craniofac Surg. 2018;29(5):1.

63. Cornely $\mathrm{C}$, Fischer $\mathrm{M}$, Ingianni $\mathrm{G}$, Isenmann $\mathrm{S}$. Greater occipital nerve neuralgia caused by pathological arterial contact: treatment by surgical decompression. Headache $\mathrm{J}$ Head Face Pain. 2011;51(4):609-12.

64. Ducic I, Felder JM, Khan N, Youn S. Greater occipital nerve excision for occipital neuralgia refractory to nerve decompression. Ann Plast Surg. 2014;72(2):184-7.

65. Gille O, Lavignolle B, Vital J-M. Surgical treatment of greater occipital neuralgia by neurolysis of the greater occipital nerve and sectioning of the inferior oblique muscle. Spine (Phila Pa 1976). 2004;29(7): 828-32.

66. Sharma RR, Devadas RV, Pawar SJ, Lad SD, Mahapatra AK. Current status of peripheral neurectomy for occipital neuralgia. Neurosurg Q. 2005;15(4): 232-8.

67. Pisapia JM, Bhowmick DA, Farber RE, Zager EL. Salvage C2 ganglionectomy after C2 nerve root decompression provides similar pain relief as a single surgical procedure for intractable occipital neuralgia. World Neurosurg. 2012;77(2):362-9.

68. Acar F, Miller J, Golshani KJ, Israel ZH, McCartney $\mathrm{S}$, Burchiel KJ. Pain relief after cervical ganglionectomy (C2 and C3) for the treatment of medically intractable occipital neuralgia. Stereotact Funct Neurosurg. 2008;86(2):106-12. 